\title{
Small-Molecule Amyloid Beta-Aggregation Inhibitors in Alzheimer's Disease Drug Development
}

\author{
Sharmin Reza Chowdhury ${ }^{1}$ Fangzhou Xie ${ }^{1}$ Jinxin Gu ${ }^{1}$ Lei Fu ${ }^{1}$ \\ ${ }^{1}$ Shanghai Key Laboratory for Molecular Engineering of Chiral Drugs, \\ School of Pharmacy, Shanghai Jiao Tong University, Shanghai, \\ People's Republic of China \\ Address for correspondence Lei Fu, Shanghai Key Laboratory for \\ Molecular Engineering of Chiral Drugs, School of Pharmacy, Shanghai \\ Jiao Tong University, Shanghai 200240, People's Republic of China \\ (e-mail: leifu@sjtu.edu.cn). \\ Pharmaceut Fronts 2019;1:e22-e32.
}

\begin{abstract}
Keywords

- Alzheimer's disease

- small molecule amyloid $\beta$ aggregation inhibitors

- drug design

Alzheimer's disease (AD) is still an incurable neurodegenerative disease that causes dementia. $A D$ changes the brain function that, over time, impairs memory and diminishes judgment and reasoning ability. Pathophysiology of AD is complex. Till now the cause of $A D$ remains unknown, but risk factors include family history and genetic predisposition. The drugs previously approved for AD treatment do not modify the disease process and only provide symptomatic improvement. Over the past few decades, research has led to significant progress in the understanding of the disease, leading to several novel strategies that may modify the disease process. One of the major developments in this direction is the amyloid $\beta(A \beta)$ aggregation. Small molecules could block the initial stages of $A \beta$ aggregation, which could be the starting point for the design and development of new AD drugs in the near future. In this review we summarize the most promising small-molecule $A \beta$-aggregation inhibitors including natural compounds, novel small molecules, and also those are in clinical trials. Moreover, we briefly summarized some reported docking studies of small-molecule $A \beta$ aggregation inhibitors. These will give us an idea about the chemical features required to design novel small molecules with anti-A $\beta$ aggregation properties.
\end{abstract}

\section{Introduction}

Alzheimer's disease (AD) is the most common form of dementia and is still an incurable, progressive neurodegenerative disorder. ${ }^{1} \mathrm{AD}$ is a multifactorial disease in which a complex of proteins, enzymes, or receptors is involved. The pathogenesis of $A D$ is not completely clear. However, the typical pathological hallmarks are amyloid $\beta(A \beta)$ deposits, tau $(\tau)$ protein aggregation, oxidative stress, and decreased levels of acetylcholine $(\mathrm{ACh})$ in the brain. ${ }^{2}$ The etiological mechanisms underlying the neuropathological changes in AD remain unclear but are probably affected by both environmental and genetic factors. ${ }^{3}$ $\mathrm{AD}$ is characterized by relatively slow, chronic but progressive neurodegeneration and impairment in cognition accompanied by abnormal behavior and personality changes, ultimately leading to full dementia. Incidence increases with age, affect- ing an estimated 35 million patients worldwide. ${ }^{4}$ However, since dementia primarily affects those aged over 60 , increased longevity has led to increased rates of $\mathrm{AD} .^{5}$

Currently there are no effective treatments or interventions to mitigate $A D$ progression, and the incidence rates for $A D$ doubled every 5 years from age 65 . The global burden of $A D$ patients is therefore expected to be 106.8 million by $2050 .^{6}$ Current treatment of the disease, essentially symptomatic, is based on three cholinesterase inhibitors (donepezil, galantamine, and rivastigmine) and memantine, affecting the glutamatergic system (-Table 1). Unfortunately, none of these drugs stop the progressive loss of neurons and there is no treatment that can halt the progressive deterioration of cognitive faculties in AD patients. ${ }^{7}$ Despite enormous information gained, the prevailing hypotheses regarding $\mathrm{AD}$ pathogenesis have failed to deliver strategies for mitigation of symptoms. ${ }^{8}$ 
Table 1 Medication for Alzheimer's disease

\begin{tabular}{|c|c|c|c|}
\hline $\begin{array}{l}\text { Drug } \\
\text { name }\end{array}$ & $\begin{array}{l}\text { Brand } \\
\text { name }\end{array}$ & Structure & $\begin{array}{l}\text { FDA } \\
\text { approved in }\end{array}$ \\
\hline Donepezil & Aricept & & 1996 \\
\hline Galantamine & Razadyne & & 2001 \\
\hline Memantine & Namenda & & 2003 \\
\hline Rivastigmine & Exelon & & 2000 \\
\hline $\begin{array}{l}\text { Donepezil + } \\
\text { Memantine }\end{array}$ & Namzaric & & 2014 \\
\hline
\end{tabular}

Abbreviation: FDA, U.S. Food and Drug Administration.

\section{Amyloid Cascade Hypothesis of Alzheimer's Disease}

The amyloid hypothesis proposes $A \beta$ as the main cause of the disease. It suggests that misfolding of the extracellular $A \beta$ protein accumulated in senile plaques (SPs) and the intracellular deposition of misfolded tau protein in neurofibrillary tangles (NFTs) cause memory loss and confusion (also cause personality and cognitive decline over time). Accumulated $A \beta$ peptide is the main component of SPs and is derived from the proteolytic cleavage of a larger glycoprotein named amyloid precursor protein (APP). APP is a transmembrane protein that plays an important role in a range of biological activities, including neuronal development, signaling, intracellular transport, and other aspects of neuronal homeostasis. APP is the precursor molecule cut by $\beta$ - and $\gamma$-secretases to produce a 37 to 49 amino acid residue peptide. $A \beta$ lies at the heart of the amyloid cascade hypothesis and its amyloid fibrillar form is the primary component of amyloid plaques found in the brains of $A D$ patients. ${ }^{9-15} A \beta$ peptides are mainly observed in the region of the hippocampus and the neocortex as well as in the cerebrovasculature. ${ }^{9-13}$ Human
APP can be processed via two alternative pathways: amyloidogenic and nonamyloidogenic. APP is first cleaved by $\alpha-$ secretase (nonamyloidogenic pathway) or $\beta$-secretase (amyloidogenic pathway), generating membrane-tethered $\alpha$ - or $\beta-C$ terminal fragments. ${ }^{9}$

Since the first description of presenile dementia by Alois Alzheimer in 1907, SPs and NFTs are considered as the key pathological hallmarks of AD. The identification of A $\beta$ in SPs and genetic studies that identified mutations in the APP, presenilin 1 (PSEN1), and presenilin 2 (PSEN2) genes leading to the accumulation of $A \beta$ and early-onset familial dementia resulted in the formulation of the "amyloid cascade hypothesis."15,16

The enzymatic processes responsible for the metabolism of APP to A $\beta$ are now reasonably well understood. APP is sequentially cleaved by $\beta$ - and $\gamma$-secretases. $\beta$-Secretase first cleaves APP to release a large secreted derivative, sAPP $\beta$. A fragment of 99 amino acids remains membrane bound, and is rapidly cleaved by $\gamma$-secretase to generate $A \beta$. Hence, numerous different $A \beta$ species exist, but those ending at position 40 (A $\beta 40)$ are the most abundant ones ( $\sim 80-90 \%)$, followed by $A \beta 42$ ( 5-10\%). The longer forms of $A \beta$, particularly $A \beta 42$, are more hydrophobic, fibrillogenic, and are the principal species deposited in the brain. ${ }^{9}$

The primary amino acid sequence of $A \beta$ ( - Fig. 1) was first discovered from extracellular deposits and amyloid plaques in 1984. A $\beta$ monomers aggregate into various types of assemblies, including oligomers, protofibrils, and amyloid fibrils (-Fig. 2). Amyloid fibrils are larger and insoluble, and they can further assemble into amyloid plaques. While amyloid oligomers are soluble and may spread throughout the brain. Amyloid plaques with $A \beta$ as the main component are most commonly found in the neocortex in the brain of AD patients. ${ }^{9}$ Amyloid cascade hypothesis (-Fig. $\mathbf{3}$ ) proposes that the deposition of $A \beta$ is the initial pathological event in AD leading to the formation of SPS and then to NFTs, neuronal cell death, and ultimately dementia. While there is substantial evidence supporting the hypothesis, there are also limitations, such as SPs and NFTs may develop independently, and SPs and NFTs may be the products rather than the causes of neurodegeneration in $\mathrm{AD} .{ }^{15}$ On the other hand, tau $(\tau)$ proteins are also found in several less common neurodegenerative diseases, notably in the absence of neurotic plaques. The NFTs in the different diseases have some distinctive morphological features and may exhibit a distinct composition of tau isoforms that differ from AD. ${ }^{17,18}$

In contrast, the amount of oligomeric $A B$ is increased in $A D$ brain extracts. $A \beta$ oligomers trigger synapse failure and memory impairment, resulting in impaired brain function in the final stages of the disease. Further studies reported that cognitive deficits appeared before plaque deposition or the detection of insoluble amyloid fibrils. These all evidence proved that $A \beta$ oligomers trigger neuronal death rather than insoluble fibrils or plaques. $^{9}$

\section{Current Trend of AD Research}

AD has been studied over a century, but acetylcholinesterase inhibitors and memantine are the only drugs currently approved for its management (-Table 1). These drugs 


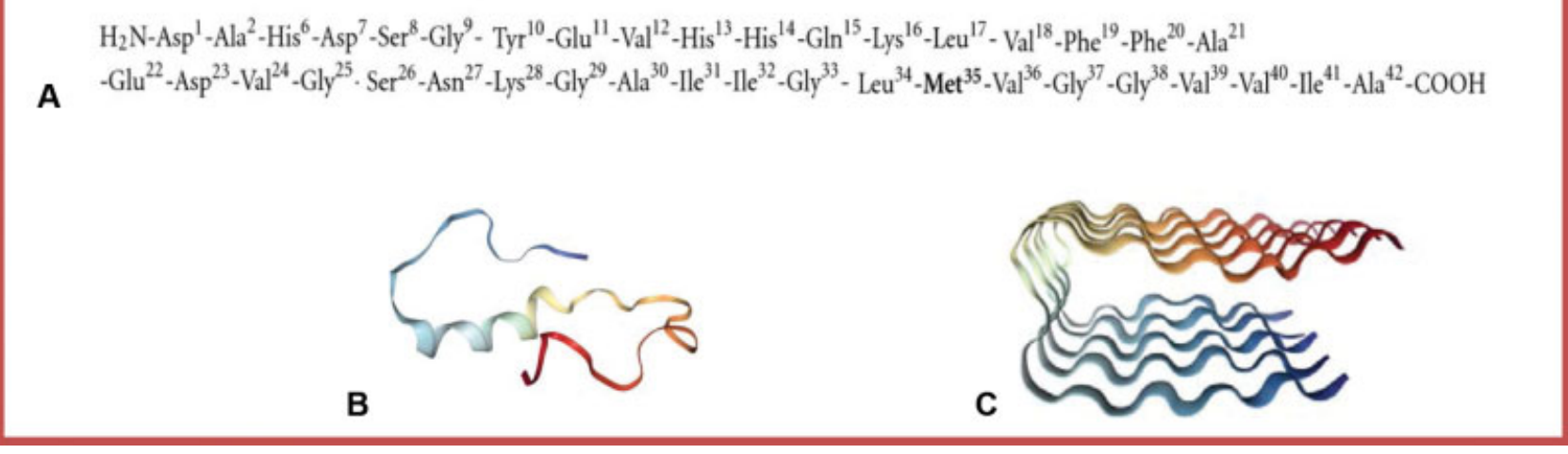

Fig. 1 Structure of $A \beta$ monomer and fibrils. (A) The primary amino acid sequence of the 42 -amino acid $A \beta$, (B) $3 D$ structure of $A \beta 1-40$ monomer (PDB code: 2LFM), and (C) A 1 1-42 fibrils, homopentamer structure (PDB code: $2 B E G$ ).



Fig. 2 Conversion of amyloid $\beta(A \beta)$ monomers to oligomers, protofibrils and fibrils.

provide symptomatic improvement alone but do less to modify the disease process. The extensive insight into the molecular and cellular pathomechanism in AD over the past few decades has provided us significant progress in the understanding of the disease. Several novel strategies that seek to modify the disease process have been developed. ${ }^{1}$

Current directions in the search for novel, potentially effective agents for the treatment of $A D$ include agents acting upon $A \beta$ (early-stage intervention), such as vaccines, antibodies, and small-molecule inhibitors or modulators of $\beta$ and $\gamma$-secretases; agents directed against the tau protein as well as compounds acting as antagonists of neurotransmitter (mild-stage intervention), and agents targeting microglia or some anti-inflammation (late-stage intervention) (-Fig. 4). The major developments in the amyloid and tau-based therapeutics could hold the key to treatment of $A D$ in the near future. ${ }^{1}$ Development of new effective drugs acting upon the central nervous system is usually a difficult and time-consuming process, and in the case of $\mathrm{AD}$ to date clinical trials have had a very high failure rate. Most of phase II clinical trials end with a positive outcome, but do not succeed in phase III, often due to serious adverse effects or lack of therapeutic efficacy. Now it becomes one of the greatest challenges in modern medicine to develop novel drugs with strong disease-modifying properties. ${ }^{19,20}$

Several large clinical trials are actively studying individuals to discover potential therapies by $2025 .^{21}$ Preclinical studies performed in academic as well as industrial settings focus on many potential molecular targets involved in the pathogenesis of $\mathrm{AD}$. Because of a huge attrition rate, only selected candidates are accepted into clinical trials as potential anti-AD agents. Due to the importance of these studies, several comprehensive reviews on anti-AD drug development prospects have been published in recent years. ${ }^{1,22-27}$ In 


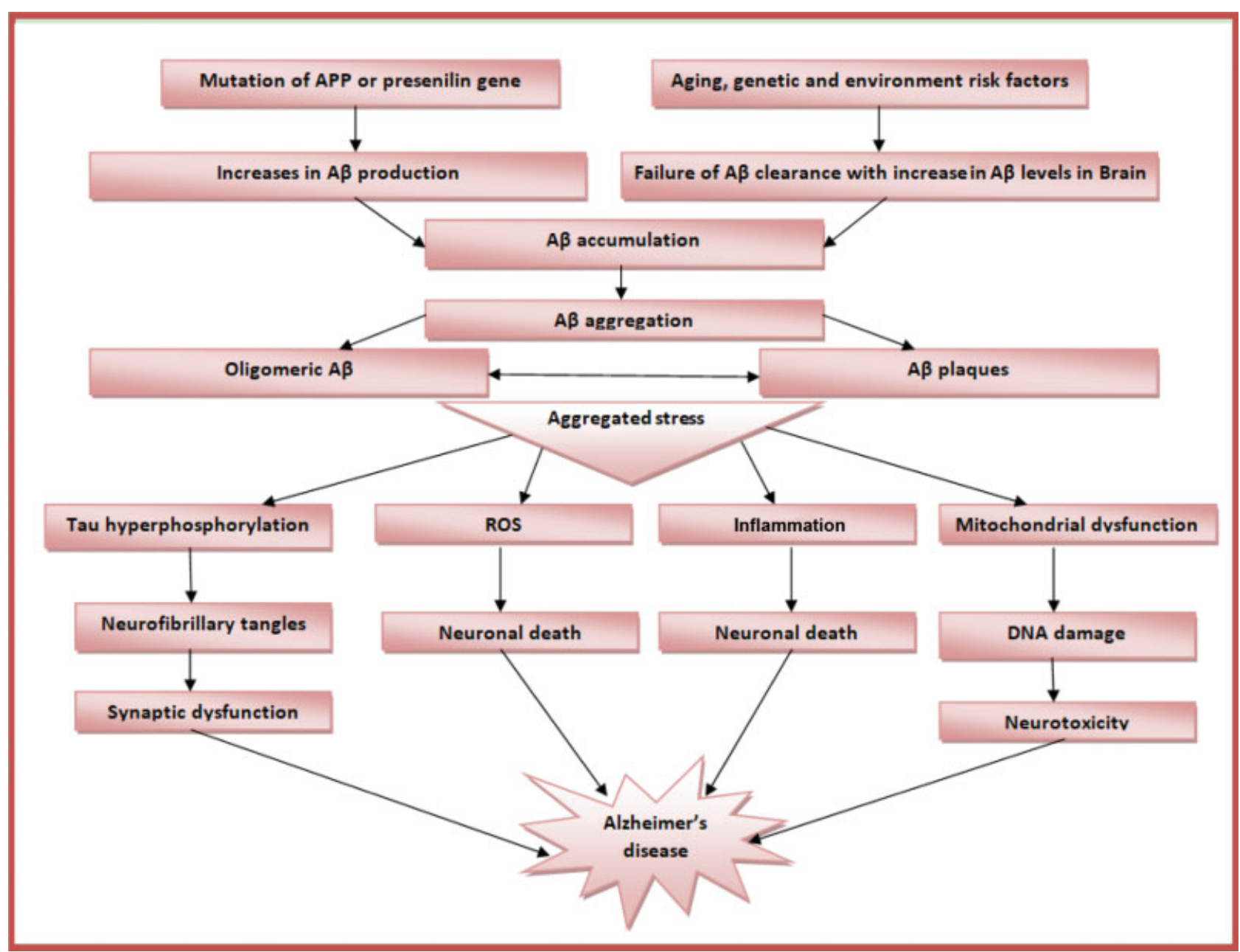

Fig. 3 Proposed amyloid cascade hypothesis.

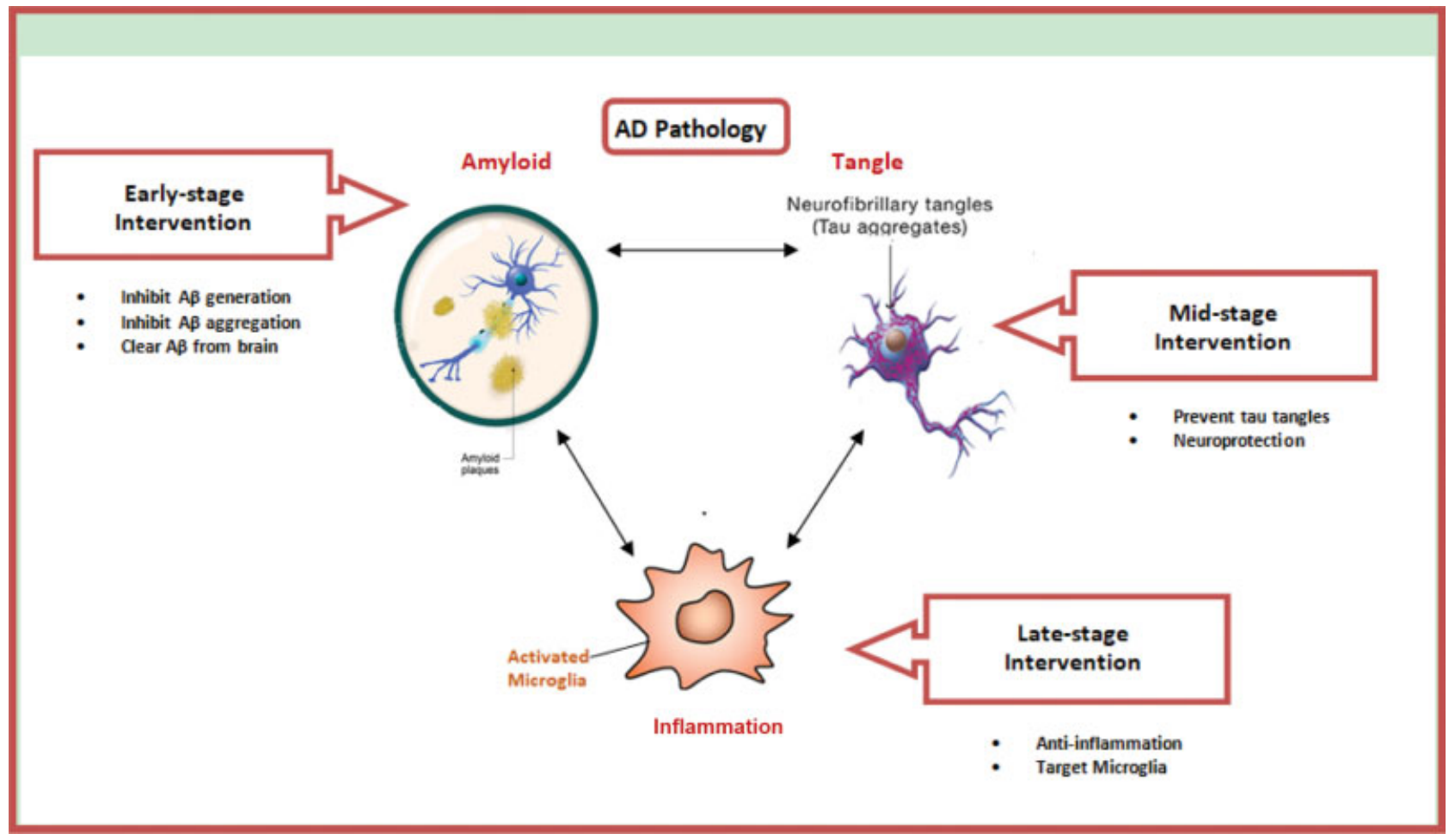

Fig. 4 Current trend of Alzheimer's disease research. 
this review we present the latest advances in the scope of the most promising small-molecule $A \beta$-aggregation inhibitors that are currently undergoing $\mathrm{AD}$ drug development and clinical trials.

\section{Small-Molecule Amyloid ß-Aggregation Inhibitors}

The progressive production and subsequent accumulation of $A B$ play a central role in $A D$. $A \beta$ is released in a soluble form that may be responsible for cognitive dysfunction in the early stages of the disease, then progressively forms oligomeric, multimeric, and fibrillar aggregates, triggering neurodegeneration. Eventually, the aggregation and accumulation of $A B$ culminates with the formation of extracellular plaques, one of the morphological hallmarks of $\mathrm{AD}$. Based on the conformation/oligomerization hypothesis, molecules able to stabilize the soluble $A \beta$ conformation destabilize the altered amyloidogenic conformer or prevent the required conformational transition, which could be effective inhibitors of amyloid plaque formation. These could be very potent drug candidates for AD treatment. ${ }^{28}$ Indeed, recent and ongoing clinical trials in $\mathrm{AD}$ continue to experiment with very early drug interventions in attempts to develop a disease-modifying agent but unfortunately, so far, no such approved agents are currently available. ${ }^{29}$ Some small molecules are able to inhibit the formation and extension of $A \beta$ fibrils, and also destabilize $A \beta$ fibrils in vitro. These include natural compounds or commercially available bioactive compounds, drugs, surfactants, $\mathrm{Cu} / \mathrm{Zn}$ chelators, phenothiazines, and sulfonated dyes such as Congo red (CR) and thioflavin $T$ (ThT) ${ }^{30-32}$ As the strategy of inhibiting $A \beta$ aggregation has increasingly gained acceptance, greater numbers of inhibitors have been developed and the structure-activity relationships of potent inhibitors have been systematically explored. ${ }^{28,33,34} \mathrm{CR}$ was the first small molecule reported to bind to amyloid in tissue sections. ${ }^{35}$ Later ThT and thioflavin S were also shown to stain amyloid deposits. CR and ThT, the two dyes (-Fig. 5), are the classical reagents to detect characteristic $A \beta$ sheet-mediated fibrillization. CR and ThT have also been shown to inhibit $A \beta$ fibril formation at higher concentrations. ${ }^{36,37}$

\section{Anti-A $\beta$ Natural Compounds}

Several plant-derived natural compounds are known to exhibit antiamyloid aggregation activity which makes them attractive as potential therapies to treat AD. These natural compounds are known to exhibit direct binding to various amyloid species including oligomers and fibrils, which in turn can lead to conformational change in the $\beta$-sheet assembly to form nontoxic aggregates. ${ }^{40}$ Several polyphenols (-Fig. 6), including curcumin, resveratrol, and epigallocatechin-3-gallate (EGCG), have progressed to clinical trials for AD treatment. Moreover, based on their multiple functions, including antioxidant, antiinflammatory, and metal chelating capacities, polyphenols are a rich source for a variety of different structural backbones that can be utilized in rational drug design efforts to find multifunctional antiamyloid agents. ${ }^{38-41}$ Several recent reviews summarized the progress in natural product-based amyloid inhibitors and also analyzed their mechanisms of inhibition in vitro. $^{38,39}$

\section{Small Molecules in Clinical Trials}

Compounds such as small molecules that target specific $A \beta$ subregions represent the first generation of amyloid-based therapeutics with the potential to demonstrate diseasemodifying activity. Although the results of ongoing clinical trials are inconclusive, these compounds hold the promise of a new day in the development of disease-modifying therapies for AD. ${ }^{42}$

Phase III clinical trials are currently underway for agent ALZT-OP1 developed by AZ Therapeutics ${ }^{43}$ for the prevention and treatment of early AD. It is a combination drug therapy consisting of the administration of two previously approved drugs, which have been shown to inhibit $A \beta$ aggregation and neuroinflammation. GV-971 (Shanghai Green Valley) is a sodium oligo-mannurarate developed for the oral treatment of mild-to-moderate $\mathrm{AD}$ and its phase III clinical trials also finished on October 25, 2018 as a safe, well-tolerated oral drug. It showed the ability to reduce the toxicity of $A \beta$ peptide in vitro. ${ }^{44,45}$ KHK6640 (Kyowa Hakko Kirin Pharma), also an $A \beta$ aggregation inhibitor, is in phase III clinical trial. ${ }^{46}$

Phase II clinical trials include several low-molecular-weight compounds that could be attributed to the general group of "antiamyloidogenic" drugs. ${ }^{47}$ Scyllo-Inositol (ELND005) ${ }^{48}$ is a small-molecule inhibitor of $A \beta$ aggregation in phase II/III clinical development at Transition Therapeutics for the oral treatment of AD. Posiphen, ${ }^{49}$ discovered by the U.S. National Institute on Aging, is a small, orally active antiamyloidogenic agent which is in phase II clinical trials for the treatment of AD and Parkinson's disease. Bexarotene (Cleveland Clinic) is a U.S. Food and Drug Administration approved anticancer agent but is not approved for the use of $A D$. It reduced $A \beta$ in the brain in experimental models of $\mathrm{AD}$, currently in phase II clinical study.

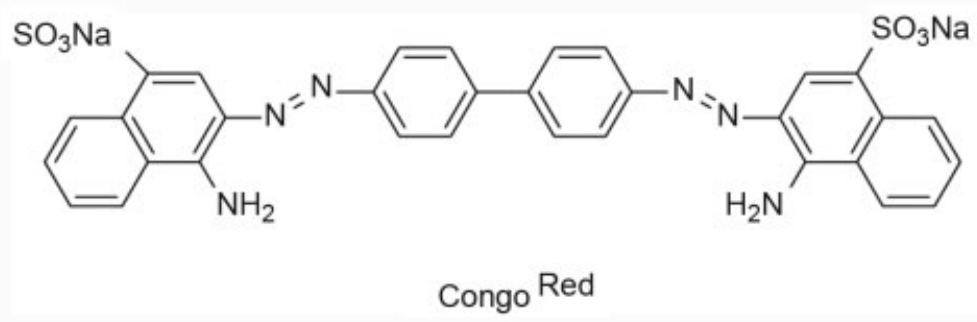

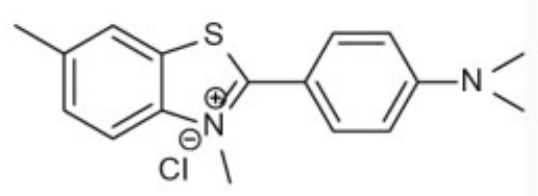

Thioflavin T

Fig. 5 Chemical structures of Congo red and thioflavin T. 
<smiles>COc1cc(/C=C/C=C(O)/C=C/C(=O)/C=C/c2ccc(O)c(OC)c2)ccc1O</smiles>

Curcumin<smiles>O=C(O[C@H]1Cc2c(O)cc(O)cc2O[C@H]1c1cc(O)c(O)c(O)c1)c1cc(O)c(O)c(O)c1</smiles><smiles>Oc1ccc(/C=C/c2cc(O)cc(O)c2)cc1</smiles>

Resveratrol<smiles></smiles>

Epigallocatechin gallate(EGCG)<smiles>O=c1c(O)c(-c2ccc(O)cc2O)oc2cc(O)cc(O)c12</smiles>

Morin<smiles>O=c1cc(-c2ccc(O)cc2)oc2cc(O)cc(O)c12</smiles>

Apigenin

Fig. 6 Chemical structures of natural products identified as inhibitors of amyloid $\beta$ aggregation.

AZD-3293 (AstraZeneca) is in phase I clinical study. Successfully it finished single and multiple ascending dose studies on Japanese volunteers. PPI1019 (PRAECIS Pharmaceuticals Inc.) is in phase I trial, completed single-dose escalation safety study of PPI-1019 in patients with mild-moderate AD. AD-04 (German Center for Neurodegenerative Diseases) is in phase I clinical trial (www.clinicaltrials.gov).ALZ-801 (Alzheon) ${ }^{50}$ and Ro-63-8695 (GlaxoSmithKline) ${ }^{51}$ target amyloid aggregation and are currently in phase I trials. Phase I clinical trials are initiated for SAN61 (Diamedica company) and Exebryl-1 (Proteo Tech) also as a potential dual-action small molecule. Both simultaneously work as an inhibitor on amyloid plaques and neurofibrillary aggregates. ${ }^{52,53}$ Available structures of some small-molecule A $\beta$-aggregation inhibitors are summarized in - Fig. 7. ${ }^{42,47}$

\section{Molecular Docking Studies of Small- Molecule Amyloid $\beta$-aggregation Inhibitors}

Studies suggest that monomeric $A B$ is nontoxic and prevents neuronal cell death caused by oxidative stress. ${ }^{54}$ The toxic<smiles>NCCCC(=O)O[Mg]</smiles><smiles>COc1ccccc1OC(=O)C(C)c1ccc(CC(C)C)cc1</smiles>

ALZT-OP1<smiles>CN1CCC2(C)c3cc(OC(=O)Nc4ccccc4)ccc3N(C)C12C</smiles>

Posiphen<smiles>O=C(O)C1CCCN1C(=O)CCCCC(=O)N1CCCC1C(=O)O</smiles>

Ro-63-8695<smiles>C=C(c1ccc(C(=O)O)cc1)c1cc2c(cc1C)C(C)(C)CCC2(C)C</smiles><smiles>Cc1nccn1CC1CCc2c(c3ccccc3n2C)C1=O</smiles>

AD-04<smiles>CC#Cc1cncc(-c2ccc3c(c2)[C@@]2(N=C(C)C(N)=N2)[C@]2(CC[C@@H](OC)CC2)C3)c1</smiles>

AZD-3293

Fig. 7 Available structures of some small-molecule amyloid $\beta$-aggregation inhibitors. 
effects of aggregation-prone $A \beta$ result from conformational transition of $A \beta$ monomers from predominantly $\alpha$-helical to $\beta$-sheet structures that result in monomeric $A \beta$ aggregation and fibrillization. Therefore, preventing the conformational transition of the $A \beta$ monomer from an initial random coil or $\alpha$ - helix into a $\beta$-sheet is the primary goal of blocking $A \beta$ toxicity by small-molecule inhibitors. ${ }^{38}$

The amino acid sequence of human $\mathrm{A} \beta 42$ is: $\mathrm{NH} 2-{ }^{1} \mathrm{Asp}-{ }^{2}$ Ala- ${ }^{3}$ Glu- $-{ }^{4}$ Phe- $-{ }^{5}$ Arg- $-{ }^{6}$ His- $-{ }^{7}$ Asp- $-{ }^{8}$ Ser $-{ }^{9}$ Gly- $-{ }^{10}$ Tyr $-{ }^{11}$ Glu- $-{ }^{12}$ Val- $-{ }^{13-}$ His- ${ }^{14}$ His $-{ }^{15} \mathrm{Gln}-{ }^{16}$ Lys $-{ }^{17}$ Leu- ${ }^{18}$ Val- ${ }^{19}$ Phe- ${ }^{20}$ Phe- ${ }^{21}$ Ala- ${ }^{22-}$ Glu- ${ }^{23}$ Asp- ${ }^{24}$ Val- ${ }^{25} \mathrm{Gly}_{-}{ }^{26} \mathrm{Ser}^{27}{ }^{27}$ Asn- $-{ }^{28}$ Lys- ${ }^{29} \mathrm{Gly}^{30}{ }^{30} \mathrm{Ala}-{ }^{31}$ Ile- $-{ }^{32}$ Ile- ${ }^{33}$ Gly- $-{ }^{34}$ Leu- ${ }^{35}$ Met $-{ }^{36}$ Val- $-{ }^{37} \mathrm{Gly}_{-}{ }^{38} \mathrm{Gly}^{-}{ }^{39}$ Val- $-{ }^{40}$ Val- ${ }^{41}$ Ile- ${ }^{42}$ Ala-COOH. Residues ${ }^{1} \mathrm{Asp}-{ }^{28}$ Lys and ${ }^{29} \mathrm{Gly}-{ }^{42} \mathrm{Ala}$ respectively represent a hydrophilic domain and a hydrophobic domain. Unfolded and soluble monomeric $A \beta$ primarily have a random-coil structure when they are released into extracellular matrix. ${ }^{55}$ Conformational transition of $A \beta$ from an unfolded monomeric native state to a $\beta$-sheet happens rapidly and initiates the aggregation process to form toxic $A \beta$ oligomers. ${ }^{56} A \beta 42$ oligomers are the most toxic form and play important causal roles in $\mathrm{AD} .{ }^{9}$ Numerous studies indicate that some of the amino acid residues are responsible for the aggregation, these are (1) the fibril-forming $A \beta$ fragment: amino acid residues ${ }^{12} \mathrm{Va}-{ }^{24} \mathrm{Val}$ and ${ }^{30} \mathrm{Ala}-{ }^{40} \mathrm{Val}$, responsible for their native states, self-assembling into a $\beta$-sheet structure; ${ }^{57}$ (2) amino acid residues ${ }^{24}$ Val- ${ }^{28}$ Lys in a $\beta$-sheet conformation promote $A \beta$ oligomerization; ${ }^{58}$ (3) the nucleation site of aggregation: hexapeptide sequence ${ }^{16} \mathrm{KLVFFA}^{19}\left({ }^{16} \mathrm{Lys}^{21} \mathrm{Ala}\right)$ acting as a steric zipper, which leads to dimer formation and eventually larger aggregates; ${ }^{38,59-61}$ (4) aromatic residues in the $A \beta$ monomer, phenylalanine ( $\mathrm{Phe}^{4}, \mathrm{Phe}^{18}$ and $\mathrm{Phe}^{1}$ ), and tryptophan $\left(\mathrm{Tyr}^{10}\right.$ ) play a significant role in the $A \beta$ self-assembly process by enhanced fibril assembly kinetics; ${ }^{62,63}(5)$ the three specific sites, Arg-to-Gly, Tyr-to-Phe, and His-to-Arg, are believed to be important in $A \beta$ aggregation or $A \beta$-induced neurotoxicity; $; 4,65$ and (6) the amino acid residues $\mathrm{His}^{13}$ and $\mathrm{Met}^{33}$ also promote toxic conformations in $A \beta$ oligomers. ${ }^{66-68}$

A wide range of natural and synthetic molecules (both large and small molecules) has been investigated for their ability to counteract $A \beta$ aggregation and toxicity. ${ }^{38,69}$ In this review, we will summarize the molecular modeling studies of some important natural and synthetic inhibitors of $A \beta$ aggregation.

\section{Curcumin}

The antiaggregating activity of curcumin (-Fig. 6) against $A \beta$ has been extensively investigated including its structural features that contribute to the antioligomerization activity. Curcumin can interact with $A \beta$ oligomers and $A \beta$ fibrils. Modeling studies have shown that curcumin interacts with the ${ }^{12} \mathrm{~V}$ and ${ }^{16} \mathrm{KLVFFA}^{19}$ residues of the $\mathrm{A} \beta .{ }^{70-72}$ Also, it interacts with ${ }^{37} \mathrm{Gly}$ in $\mathrm{A} \beta 42$ in the C-terminus of the $A \beta$ fibrils ${ }^{73}$ and the aromatic residues (Tyr, Phe, and His) in the $A \beta$ dimer. ${ }^{74}$ Another computational investigation suggested that amino acids ${ }^{16} \mathrm{~K},{ }^{17} \mathrm{~L},{ }^{18} \mathrm{~V}$, and ${ }^{20} \mathrm{~F}$ in ${ }^{16}$ KLVFFA $^{19}$ residues were involved in stabilizing the curcumin- $A \beta$ octamer assembly. These investigations show that curcumin binding to $A \beta$-aggregates leads to significant conformational change and shifts the equilibrium toward the formation of nontoxic $A \beta$ aggregates including dimers, oligomers, protofibrils, and fibrils in the $A \beta$-aggregation pathways which prevent neurotoxicity associated with various forms of $A \beta$-aggregates. ${ }^{75}$

\section{Resveratrol}

Several studies indicate that resveratrol (-Fig. 6) directly interacts with $A \beta$ monomers and fibrils. It inhibits $A B$ fibrillization and converts toxic oligomers into nontoxic species. Interaction between resveratrol and aromatic side residues ( ${ }^{4} \mathrm{Phe},{ }^{10} \mathrm{Tyr},{ }^{19} \mathrm{Phe}$, and $\left.{ }^{20} \mathrm{Phe}\right)$ of $\mathrm{A} \beta$ selectively remodeled $A \beta$ conformers that possess $\beta$-sheet structures into nontoxic species. Researchers found that its polyphenol aglycones and glycosides were responsible for remodeling toxic $A \beta$ oligomers into nontoxic species. ${ }^{76-79}$

\section{Epigallocatechin Gallate}

EGCG (-Fig. 6) inhibits conformational change from a random-coil to a $\beta$-sheet structure and $A \beta$ oligomers formed in the presence of EGCG. ${ }^{80}$ There are 12 important residues $\left({ }^{4} \mathrm{Phe},{ }^{5} \mathrm{Arg},{ }^{19} \mathrm{Phe},{ }^{20} \mathrm{Phe},{ }^{22} \mathrm{Glu},{ }^{28} \mathrm{Lys},{ }^{29} \mathrm{Gly},{ }^{34}\right.$ Leu to ${ }^{37} \mathrm{Gly}$, and ${ }^{41}$ Ile of $A \beta$ ) that strongly interact with EGCG. Simultaneously, the side chains of some hydrophobic residues (Phe, Met, and Ile) and the main chains of ${ }^{28}$ Lys and ${ }^{29}$ Gly provide nonpolar interactions with $A \beta$. These causes remodeling of mature $A \beta$ fibrils and toxic oligomers into smaller nontoxic aggregates with the loss of $\beta$-sheet content. ${ }^{38,81}$ Modeling studies reveal that EGCG displays an antiaggregation effect from mainly two pathways: first, EGCG binds to the native form of $A B$ through interactions with the side chains of specific residues, and second, EGCG binds to the misfolded $A \beta$ species with noncovalent interactions involving the $A \beta$ backbone and subsequently remodels toxic aggregates into small nontoxic, off-pathway oligomers. ${ }^{38}$

\section{Tramiprosate}

3-Aminopropanesulfonic acid ( - Fig. 7) targets the ${ }^{13} \mathrm{HHQK}^{16}$ subregion $\left({ }^{13} \mathrm{His}-{ }^{16} \mathrm{Lys}\right)$ at the $\mathrm{N}$-terminus of $\mathrm{A} \beta .{ }^{13} \mathrm{His}-{ }^{16} \mathrm{Lys}$ amino acids are important for oligomerization, fibril propagation, and neurotoxicity. ${ }^{42}$ Due to its structural simplicity, tramiprosate is highly specific to $A \beta$. But unfortunately, it failed in the late stages of a phase III clinical trial. ${ }^{28}$ Despite its clinical failure, the data obtained from the studies will assist us in the design and development of novel small molecules with antiamyloid aggregation properties. ${ }^{82}$

\section{Scyllo-Inositol}

Scyllo-Inositol ( - Fig. 7), a potential therapeutic compound for $A D$, has been shown to inhibit $A \beta(1-42)$ fibrillogenesis in vitro. It stabilizes cell-derived small molecular weight oligomers and reduces amyloid plaque load. Also, it has shown promise in current phase II/III clinical trials. ${ }^{48,83,84}$ Modeling studies revealed that scyllo-Inositol interacts with the C-terminus of $A B .^{42}$

\section{RS-0406}

$N, N^{\prime}$-Bis(3-hydroxyphenyl)pyridazine-3,6-diamine (-Fig. 7) is a small molecule which inhibits $A \beta 1-42$ fibrillogenesis and 
a novel $\beta$-sheet breaker. ${ }^{85}$ RS-0406 interacts with the ${ }^{16}$ KLVFFA $^{19}$ residues and inhibits $A \beta$ fibrillation. ${ }^{85,86}$

\section{New Small Molecules}

The last few years have seen a surge in the discovery of small molecules as disease-modifying therapies for AD. ${ }^{87}$ Here, we will highlight some recent developments in the design of the small-molecule $A \beta$-aggregation inhibitors as potential disease-modifying agents and briefly summarized some previously reported docking studies of these recently developed small molecules.

In a recent study, Sancho and coworkers identified compounds I-III ( - Fig. 8) as A $\beta$ aggregation inhibitors based on a high-throughput study by screening a chemically diverse compound library. ${ }^{88}$ Molecular modeling study of compound I (2-methyl-5,6,7,8-tetrahydro-4H-[1]bbenzothieno[2,3-d] $[1,3]$ oxazin-4-one) with an $A \beta$ dimer assembly showed that the tetrahydrobenzenethieno ring was in van der Waal's contact with ${ }^{16}$ KLVFFA $^{19}$ residues, whereas benzenethieno and oxazinone rings were in contact with side chains of isoleucine and leucine at the C-terminal via nonpolar contact. Modeling compound II (2,5-dichloro- $N$-(4-piperidinophenyl)3-thiophenesulfonamide) in the $A \beta$-dimer showed that the phenylpiperidine substituent was oriented toward the $N$-terminal in the LVFF region. The phenyl ring underwent T-shaped $\pi-\pi$ interaction with ${ }^{16} \mathrm{KLVFFA}^{19}$ residues. The 2,5-dichlorothiophenesulfonamide was oriented toward the C-terminal, where it was in van der Waal's contact with amino acid side chains of isoleucine, glycine, and leucine. In contrast, the modeling study of compound III ( $\mathrm{N}$-(4-chloro-2-nitrophenyl)- $N$-phenylurea) in the $A \beta$-dimer model showed that this compound only interacted at the $\mathrm{N}$-terminal region. The two phenyl rings linked to the urea moiety were in close proximity to the ${ }^{16} \mathrm{KLVFFA}^{19}$ region. Compound IV (6(4-chlorophenyl)sulfonyl)-2-phenylpyrazolo[1,5-a]pyrimidin7-amine) exhibits a V-shaped conformation in the $A \beta$ dimer assembly. The bicyclic pyrazolopyrimidine underwent $\pi$-alkyl interactions with amino acid side chains of isoleucine and leucine at the C-terminal, whereas the chlorophenyl ring interacts with the phenylalanine ring at the $\mathrm{N}$-terminal. Compared with compounds I-IV, compound IV is a larger molecule, longer along its axis, which helps in making additional contacts in the steric-zipper assembly and provides better interaction. ${ }^{87,88}$

Luo and coworkers reported the design of novel tacrinealkoxybenzene hybrids, compound V ( - Fig. 8), as dual inhibitors of cholinesterases and $A \beta$ aggregation. They reported that these compounds were able to prevent self-induced $A \beta$-aggregation. ${ }^{89}$ The tetrahydroacridine ring was oriented toward the LVFF region, where it underwent $\pi$-alkyl interactions with leucine and valine side chains of ${ }^{16}{ }^{K L V F F A}{ }^{19}$ residues and the $\mathrm{NH}$ of tetrahydroacridine ring formed a hydrogen bond with the backbone $\mathrm{C}=\mathrm{O}$ of valine. ${ }^{87,89}$

Kanai and coworkers reported compound VI (4-benzyl-Nisoneopentyl-6-phenoxypicolinamide, -Fig. 8), which exhibited dose-dependent inhibition of $A \beta$ aggregation. ${ }^{90}$

Modeling study of compound VI in the steric-zipper model showed that it exhibited a Y-shaped conformation. Benzyl, phenoxy, and pyridine aromatic rings undergo $\pi-\pi$ stacked interactions with phenylalanine rings on either side of stericzipper interface. Significantly, the isopentyl side chain undergoes several nonpolar contacts with side chains of<smiles>Cc1nc2sc3c(c2c(=O)o1)CCCC3</smiles>

I<smiles>O=S(=O)(Nc1ccc(N2CCCCC2)cc1)c1cc(Cl)sc1Cl</smiles>

II<smiles>COc1cc(CNCCCCCCNc2c3c(nc4ccccc24)CCCC3)cc2c1OCO2</smiles><smiles>O=C(Nc1ccccc1)Nc1ccc(Cl)cc1[N+](=O)[O-]</smiles>

III<smiles>C/C=C\C=C/C=C\c1cc2ncc(S(=O)(=O)c3ccc(Cl)cc3)c(N)n2n1</smiles>

IV<smiles>CC(C)CCNC(=O)c1cc(Cc2ccccc2)cc(Oc2ccccc2)n1</smiles>

VI<smiles>O=C1c2ccccc2C(=O)N1CCCCCNCc1ccc(F)cc1</smiles><smiles>Fc1ccc(-c2cc(NCCNc3cc(-c4ccc(F)cc4)[nH]n3)n[nH]2)cc1</smiles>

VIII<smiles>[X][X]c1nc(Oc2ccc(C(=O)OCC(C)N(C)C)cc2)nc(Oc2nc(OC)nc(Oc3ccc(C(=O)OCC(C)N(C)C)cc3)n2)n1</smiles>

Fig. 8 Recently developed some small-molecule amyloid $\beta$-aggregation inhibitors. 
phenylalanine and valine, respectively, and the pyridine nitrogen forms hydrogen bonds with lysine side chains. ${ }^{87,90}$

Inspired by the chemical structure of the cholinesterase inhibitor donepezil (-Table 1), Malawska and coworkers developed heterodimeric isoindoline-1,3-dione derivatives of AChE inhibitors with anti-A $\beta$ aggregation activity. ${ }^{91}$ Molecular modeling of the most potent isoindoline-1,3-dione derivative VII (2-(5-(4-fluorobenzylamino)pentyl)isodindoline-1,3-dione) (-Fig. 8) showed that it exhibited a linear binding mode with the steric-zipper assembly. The isoindole ring undergoes multiple $\pi$-alkyl and $\pi-\pi$ interactions with side chains of valine and phenylalanine, respectively, with $<5 \AA$ distance. The fluorobenzene substituent undergoes $\pi$ alkyl interactions with valine side chains on either side and more interestingly, the fluorine atom forms hydrogen bonds with lysine side chains. These multiple polar and nonpolar contacts are able to stabilize the steric-zipper assembly, which can lead to conformational changes and reduce the cytotoxicity of $A \beta$ aggregates. ${ }^{87,91}$

In a recent study, Muhs and coworkers used a rational design approach to develop small molecules based on a 3aminopyrazole scaffold. ${ }^{92}$ The idea was to design small molecules that can undergo complimentary interactions with the donor-acceptor-donor hydrogen bonding pattern seen in the $\beta$-sheet assembly of $A \beta$. This approach led to the identification of dimeric 3-aminopyrazole derivatives VIII and IX ( - Fig. 8) that were able to prevent $A \beta$ oligomerization, fibril formation, and reduce cytotoxicity. ${ }^{87,92}$ The most potent compound IX formed a more stable complex in the steric-zipper octamer assembly, exhibited a linear conformation, and is able to fit nicely at the steric-zipper interface. The phenylpyrazole moieties underwent $\pi-\pi, \pi$-alkyl, and $\pi$-cation interactions with phenylalanine, valine, and lysine amino acid residues respectively on either side of the stericzipper interface. These results support anti-A $\beta$ aggregation properties of compound $\mathbf{I X} .^{87,93}$

A novel small library of triazine-based small molecules was reported as multitargeting agents with dual cholinesterase and amyloid inhibition. ${ }^{93}$ The most potent triazine compound $\mathbf{X}$ (-Fig. 8) undergoes favorable interactions with several amino acids located at both the $\mathrm{C}$ - and $\mathrm{N}$-terminals the $\mathrm{A} \beta$ dimer model due to its larger size of the compound. The central triazine ring with two dimethylaminopropyl benzoate units was oriented closer to the ${ }^{16}$ KLVFFAED $^{21}$ region with the triazine and benzoate aromatic rings undergoing $\pi-\pi$ stacking contacts with phenylalanine and alanine side chains. However, the presence of three ionizable groups (tertiary amines) will diminish its blood-brain barrier permeability. ${ }^{87,93}$

\section{Future Perspectives}

Currently there were 132 agents in 156 trials of anti-AD therapies. ${ }^{94}$ According to the Cummings et al's review, in 2018 a total of 26 agents were in phase III trial. Among them $54 \%$ are anti-amyloid (three are antiaggregation). ${ }^{95}$ Recent reviews show that lessons are learned from all trials; even negative and futile outcomes are highly informative and provide guidance for future trials. ${ }^{94}$ Although the results of ongoing clinical trials are inconclusive, these compounds hold the promise of a new day in the development of diseasemodifying therapies for AD. As our knowledge of their molecular structures and the molecular interactions responsible for activity of small molecules advances, more new generation of small-molecule $A \beta$-aggregation inhibitors will be developed in the near future. Effective drugs will have a dramatic impact on the number of persons affected in the future and also the quality of life of the $\mathrm{AD}$ patients. Advanced research in the field of AD will lead us to a better future for aging populations.

\section{Conclusion}

$\mathrm{AD}$ is still an incurable neurodegenerative disorder that has proved challenging to manage and treat with current therapies. Disease modification is the ultimate goal for AD drug development but has, so far, remained elusive. In this circumstance, small-molecule $A \beta$-aggregation inhibitors could be the key to treat $A D$.

\section{Conflict of Interest}

The authors declare no conflict of interest.

\section{Reference}

1 Godyń J, Jończyk J, Panek D, Malawska B. Therapeutic strategies for Alzheimer's disease in clinical trials. Pharmacol Rep 2016;68 (01):127-138

2 Baharloo F, Moslemin MH, Nadri H, et al. Benzofuran-derived benzylpyridinium bromides as potent acetylcholinesterase inhibitors. Eur J Med Chem 2015;93:196-201

3 Reitz C, Brayne C, Mayeux R. Epidemiology of Alzheimer disease. Nat Rev Neurol 2011;7(03):137-152

4 Wimo A, Jönsson L, Bond J, Prince M, Winblad B; Alzheimer Disease International. The worldwide economic impact of dementia 2010. Alzheimers Dement 2013;9(01):1.e3-11.e3

5 Prince MJ, Acosta D, Castro-Costa E, Jackson J, Shaji KS. Packages of care for dementia in low- and middle-income countries. PLoS Med 2009;6(11):e1000176

6 Brookmeyer R, Johnson E, Ziegler-Graham K, Arrighi HM. Forecasting the global burden of Alzheimer's disease. Alzheimers Dement 2007;3(03):186-191

7 Ahmad SS, Akhtar S, Jamal QM, et al. Multiple targets for the management of Alzheimer's disease. CNS Neurol Disord Drug Targets 2016;15(10):1279-1289

8 Meyer PF, Savard M, Poirier J, Morgan D, Breitner J; Alzheimer's Disease Neuroimaging Initiative. Hypothesis: cerebrospinal fluid protein markers suggest a pathway toward symptomatic resil-

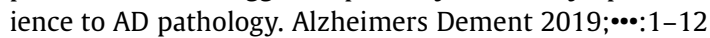

9 Chen GF, Xu TH, Yan Y, et al. Amyloid beta: structure, biology and structure-based therapeutic development. Acta Pharmacol Sin 2017;38(09):1205-1235

10 Haass C, Selkoe DJ. Cellular processing of beta-amyloid precursor protein and the genesis of amyloid beta-peptide. Cell 1993;75 (06):1039-1042

11 Glenner GG, Wong CW. Alzheimer's disease: initial report of the purification and characterization of a novel cerebrovascular amyloid protein. 1984. Biochem Biophys Res Commun 2012; 425(03):534-539

12 Selkoe DJ, Hardy J. The amyloid hypothesis of Alzheimer's disease at 25 years. EMBO Mol Med 2016;8(06):595-608

13 Viswanathan A, Greenberg SM. Cerebral amyloid angiopathy in the elderly. Ann Neurol 2011;70(06):871-880 
14 Nunan J, Small DH. Regulation of APP cleavage by alpha-, beta- and gamma-secretases. FEBS Lett 2000;483(01):6-10

15 Reitz C. Alzheimer's disease and the amyloid cascade hypothesis: a critical review. Int J Alzheimers Dis 2012;2012:369808

16 About a peculiar disease of the cerebral cortex. By Alois Alzheimer, 1907 (Translated by L. Jarvik and H. Greenson). Alzheimer Dis Assoc Disord 1987;1(01):3-8

17 Michaelis ML. Drugs targeting Alzheimer's disease: some things old and some things new. J Pharmacol Exp Ther 2003;304(03): 897-904

18 Murphy MP, LeVine H III. Alzheimer's disease and the amyloid- $\beta$ peptide. J Alzheimers Dis 2010;19(01):311-323

19 Robinson DM, Keating GM. Memantine: a review of its use in Alzheimer's disease. Drugs 2006;66(11):1515-1534

20 Ghezzi L, Scarpini E, Galimberti D. Disease-modifying drugs in Alzheimer's disease. Drug Des Devel Ther 2013;7:1471-1478

21 Stites SD, Rubright JD, Karlawish J. What features of stigma do the public most commonly attribute to Alzheimer's disease dementia? Results of a survey of the U.S. general public. Alzheimers Dement 2018;14(07):925-932

22 Lundkvist J, Halldin MM, Sandin J, et al. The battle of Alzheimer's disease - the beginning of the future unleashing the potential of academic discoveries. Front Pharmacol 2014;5:102

23 Schneider LS, Mangialasche F, Andreasen N, et al. Clinical trials and late-stage drug development for Alzheimer's disease: an appraisal from 1984 to 2014. J Intern Med 2014;275(03):251-283

24 Zheng H, Fridkin M, Youdim M. New approaches to treating Alzheimer's disease. Perspect Medicin Chem 2015;7:1-8

25 Wisniewski T, Goñi F. Immunotherapy for Alzheimer's disease. Biochem Pharmacol 2014;88(04):499-507

26 Jia Q Deng Y, Qing H. Potential therapeutic strategies for Alzheimer's disease targeting or beyond $\beta$-amyloid: insights from clinical trials. BioMed Res Int 2014;2014:837157

27 Kumar A, Singh A, Ekavali. . A review on Alzheimer's disease pathophysiology and its management: an update. Pharmacol Rep 2015;67(02):195-203

28 Re F, Airoldi C, Zona C, et al. Beta amyloid aggregation inhibitors: small molecules as candidate drugs for therapy of Alzheimer's disease. Curr Med Chem 2010;17(27):2990-3006

29 Judge D, Roberts J, Khandker R, Ambegaonkar B, Black CM. Physician perceptions about the barriers to prompt diagnosis of mild cognitive impairment and Alzheimer's disease. Int J Alzheimers Dis 2019;2019:3637954

30 Bush AI. Metal complexing agents as therapies for Alzheimer's disease. Neurobiol Aging 2002;23(06):1031-1038

31 Taniguchi S, Suzuki N, Masuda M, et al. Inhibition of heparininduced tau filament formation by phenothiazines, polyphenols, and porphyrins. J Biol Chem 2005;280(09):7614-7623

32 Pollack SJ, Sadler IIJ, Hawtin SR, Tailor VJ, Shearman MS. Sulfonated dyes attenuate the toxic effects of $\beta$-amyloid in a structurespecific fashion. Neurosci Lett 1995;197(03):211-214

33 Porat Y, Abramowitz A, Gazit E. Inhibition of amyloid fibril formation by polyphenols: structural similarity and aromatic interactions as a common inhibition mechanism. Chem Biol Drug Des 2006;67(01):27-37

34 Reinke AA, Gestwicki JE. Structure-activity relationships of amyloid beta-aggregation inhibitors based on curcumin: influence of linker length and flexibility. Chem Biol Drug Des 2007;70(03): 206-215

35 Wu C, Scott J, Shea JE. Binding of Congo red to amyloid protofibrils of the Alzheimer $A \beta(9-40)$ peptide probed by molecular dynamics simulations. Biophys J 2012;103(03):550-557

36 Lorenzo A, Yankner BA. Beta-amyloid neurotoxicity requires fibril formation and is inhibited by congo red. Proc Natl Acad Sci U S A 1994;91(25):12243-12247

37 Xie Y, Deng S, Chen Z, Yan S, Landry DW. Identification of smallmolecule inhibitors of the Abeta-ABAD interaction. Bioorg Med Chem Lett 2006;16(17):4657-4660
$38 \mathrm{Bu}$ XL, Rao PPN, Wang YJ. Anti-amyloid aggregation activity of natural compounds: implications for Alzheimer's drug discovery. Mol Neurobiol 2016;53(06):3565-3575

39 Velander P, Wu L, Henderson F, Zhang S, Bevan DR, Xu B. Natural product-based amyloid inhibitors. Biochem Pharmacol 2017; 139:40-55

40 Savelieff MG, DeToma AS, Derrick JS, Lim MH. The ongoing search for small molecules to study metal-associated amyloid- $\beta$ species in Alzheimer's disease. Acc Chem Res 2014;47(08):2475-2482

41 Korshavn KJ, Jang M, Kwak YJ, et al. Reactivity of metal-free and metal-associated amyloid-beta with glycosylated polyphenols and their esterified derivatives. Sci Rep 2015;5:17842

42 Nie Q, Du XG, Geng MY. Small molecule inhibitors of amyloid $\beta$ peptide aggregation as a potential therapeutic strategy for Alzheimer's disease. Acta Pharmacol Sin 2011;32(05):545-551

43 NIH. U.S National Library of Medicine. Clinical Trials.gov publication. Safety and efficacy study ofALZT-OP1 in subjects with evidence of early Alzheimer's disease (NCT02547818). Available at: https:// clinicaltrials.gov/ct2/show/NCT02547818. Accessed September 11, 2015

44 NIH.U.S National Library of Medicine. Clinical Trials.gov publication. Safety, efficacy and dose titration of Sodium Oligo-mannurarate capsule on mild to moderate Alzheimer's disease (NCT01453569). Available at: https://clinicaltrials.gov/ct2/show/NCT01453569. Accessed October 18, 2011.

45 NIH.U.S National Library of Medicine. Clinical Trials.gov publication. An efficacy and safety study of sodium Oligo-mannurarate (GV-971) capsule for the treatment of Alzheimer's disease (NCT02293915). Available at: https://clinicaltrials.gov/ct2/show/NCT02293915. Accessed November 19, 2014

46 NIH.U.S National Library of Medicine. Clinical Trials.gov publication. A study of single and multiple doses of KHK6640 in subjects with prodromal or mild to moderate Alzheimer's disease (NCT02127476). Available at: https://clinicaltrials.gov/ct2/show/NCT02127476. Accessed April 30, 2014

47 Bachurin SO, Bovina EV, Ustyugov AA. Drugs in clinical trials for Alzheimer's disease: the major trends. Med Res Rev 2017;37(05): 1186-1225

48 Sinha S, Du Z, Maiti P, et al. Comparison of three amyloid assembly inhibitors: the sugar scyllo-inositol, the polyphenol epigallocatechin gallate, and the molecular tweezer CLR01. ACS Chem Neurosci 2012;3(06):451-458

49 Maccecchini ML, Chang MY, Pan C, John V, Zetterberg H, Greig NH. Posiphen as a candidate drug to lower CSF amyloid precursor protein, amyloid- $\beta$ peptide and $\tau$ levels: target engagement, tolerability and pharmacokinetics in humans. J Neurol Neurosurg Psychiatry 2012;83(09):894-902

50 Bachurin SO, Bovina EV, Ustyugov AA. Current trends in the development of drugs for the treatment of Alzheimer's disease and their clinical trials. Biomed Chem Res Methods 2018;1(03): e00015

51 Suhr OB, Lundgren E, Westermark P. Transthyretin amyloidoses: new strategies for therapeutic intervention. Drugs Future 2010; 35:325

52 Vartiainen NE, Williams M, Charles ML, Stenius T, Nurmi A, Yrjanheikki J. SAN-61 protects against AB1-42, OGD and H2O2 in rat mixed cortical cultures and inhibits GSK- $3 \mathrm{~b}$. Paper presented at: 39th Society for Neuroscience Meeting; October 16, 2009; Chicago, United States

$53 \mathrm{Hu}$ Q, Cam J, Lake T, et al. Identification of Exebryl-1 and other novel small molecules as tau protein aggregation inhibitors. Alzheimer's \& Dementia: J Alzheimer's Assoc 2011;4:481

54 Zou K, Gong JS, Yanagisawa K, Michikawa M. A novel function of monomeric amyloid beta-protein serving as an antioxidant molecule against metal-induced oxidative damage. J Neurosci 2002; 22(12):4833-4841

55 Danielsson J, Jarvet J, Damberg P, Gräslund A. The Alzheimer betapeptide shows temperature-dependent transitions between left- 
handed 3-helix, beta-strand and random coil secondary structures. FEBS J 2005;272(15):3938-3949

56 Yang DS, Yip CM, Huang TH, Chakrabartty A, Fraser PE. Manipulating the amyloid-beta aggregation pathway with chemical chaperones. J Biol Chem 1999;274(46):32970-32974

57 Liu YH, Giunta B, Zhou HD, Tan J, Wang YJ. Immunotherapy for Alzheimer disease: the challenge of adverse effects. Nat Rev Neurol 2012;8(08):465-469

$58 \mathrm{Xu}$ Y, Shen J, Luo X, et al. Conformational transition of amyloid beta-peptide. Proc Natl Acad Sci U S A 2005;102(15):5403-5407

59 Landau M, Sawaya MR, Faull KF, et al. Towards a pharmacophore for amyloid. PLoS Biol 2011;9(06):e1001080

60 Rajasekhar K, Suresh SN, Manjithaya R, Govindaraju T. Rationally designed peptidomimetic modulators of a $\beta$ toxicity in Alzheimer's disease. Sci Rep 2015;5:8139

61 Arai T, Sasaki D, Araya T, Sato T, Sohma Y, Kanai M. A cyclic KLVFFderived peptide aggregation inhibitor induces the formation of less-toxic off-pathway amyloid- $\beta$ oligomers. ChemBioChem 2014;15(17):2577-2583

62 Gazit E. Mechanistic studies of the process of amyloid fibrils formation by the use of peptide fragments and analogues: implications for the design of fibrillization inhibitors. Curr Med Chem 2002;9(19):1725-1735

63 Gazit E. Global analysis of tandem aromatic octapeptide repeats: the significance of the aromatic-glycine motif. Bioinformatics 2002;18(06):880-883

64 Sarasa M, Pesini P. Natural non-trasgenic animal models for research in Alzheimer's disease. Curr Alzheimer Res 2009;6(02):171-178

65 Dai $X$, Chang P, Liu W, et al. A $\beta-40$ Y10F increases $\beta$ fibrils formation but attenuates the neurotoxicity of amyloid- $\beta$ peptide. Int J Mol Sci 2012;13(05):5324-5337

66 Barnham KJ, Haeffner F, Ciccotosto GD, et al. Tyrosine gated electron transfer is key to the toxic mechanism of Alzheimer's disease beta-amyloid. FASEB J 2004;18(12):1427-1429

67 Schöneich C. Methionine oxidation by reactive oxygen species: reaction mechanisms and relevance to Alzheimer's disease. Biochim Biophys Acta 2005;1703(02):111-119

68 Yang DS, McLaurin J, Qin K, Westaway D, Fraser PE. Examining the zinc binding site of the amyloid-beta peptide. Eur J Biochem 2000; 267(22):6692-6698

69 Cheng B, Gong H, Xiao H, Petersen RB, Zheng L, Huang K. Inhibiting toxic aggregation of amyloidogenic proteins: a therapeutic strategy for protein misfolding diseases. Biochim Biophys Acta 2013; 1830(10):4860-4871

70 Yanagisawa D, Taguchi H, Yamamoto A, Shirai N, Hirao K, Tooyama I. Curcuminoid binds to amyloid- $\beta 1-42$ oligomer and fibril. J Alzheimers Dis 2011;24(Suppl 2):33-42

71 Masuda Y, Fukuchi M, Yatagawa T, et al. Solid-state NMR analysis of interaction sites of curcumin and 42-residue amyloid $\beta$-protein fibrils. Bioorg Med Chem 2011;19(20):5967-5974

72 Orlando RA, Gonzales AM, Royer RE, Deck LM, Vander Jagt DL. A chemical analog of curcumin as an improved inhibitor of amyloid Abeta oligomerization. PLoS One 2012;7(03):e31869

73 Sato T, Kienlen-Campard P, Ahmed M, et al. Inhibitors of amyloid toxicity based on beta-sheet packing of Abeta40 and Abeta42. Biochemistry 2006;45(17):5503-5516

74 Zhao LN, Chiu SW, Benoit J, Chew LY, Mu Y. The effect of curcumin on the stability of A $\beta$ dimers. J Phys Chem B 2012;116(25):7428-7435

75 Rao PP, Mohamed T, Teckwani K, Tin G. Curcumin binding to beta amyloid: a computational study. Chem Biol Drug Des 2015;86 (04):813-820

76 Ge JF, Qiao JP, Qi CC, Wang CW, Zhou JN. The binding of resveratrol to monomer and fibril amyloid beta. Neurochem Int 2012;61(07): 1192-1201
77 Feng Y, Wang XP, Yang SG, et al. Resveratrol inhibits beta-amyloid oligomeric cytotoxicity but does not prevent oligomer formation. Neurotoxicology 2009;30(06):986-995

78 Ladiwala AR, Lin JC, Bale SS, et al. Resveratrol selectively remodels soluble oligomers and fibrils of amyloid Abeta into off-pathway conformers. J Biol Chem 2010;285(31):24228-24237

79 Ladiwala AR, Mora-Pale M, Lin JC, et al. Polyphenolic glycosides and aglycones utilize opposing pathways to selectively remodel and inactivate toxic oligomers of amyloid $\beta$. ChemBioChem 2011; 12(11):1749-1758

80 Rezai-Zadeh K, Shytle D, Sun N, et al. Green tea epigallocatechin3-gallate (EGCG) modulates amyloid precursor protein cleavage and reduces cerebral amyloidosis in Alzheimer transgenic mice. J Neurosci 2005;25(38):8807-8814

81 Bieschke J, Russ J, Friedrich RP, et al. EGCG remodels mature alphasynuclein and amyloid-beta fibrils and reduces cellular toxicity. Proc Natl Acad Sci U S A 2010;107(17):7710-7715

82 Rauk A. Why is the amyloid beta peptide of Alzheimer's disease neurotoxic? Dalton Trans 2008;(10):1273-1282

83 Shaw JE, Chio J, Dasgupta $S$, et al. $A \beta(1-42)$ assembly in the presence of scyllo-inositol derivatives: identification of an oxime linkage as important for the development of assembly inhibitors. ACS Chem Neurosci 2012;3(03):167-177

84 Sun Y, Zhang G, Hawkes CA, Shaw JE, McLaurin J, Nitz M. Synthesis of scyllo-inositol derivatives and their effects on amyloid beta peptide aggregation. Bioorg Med Chem 2008;16(15):7177-7184

85 O'Hare E, Scopes DI, Treherne JM, Norwood K, Spanswick D, Kim EM. RS-0406 arrests amyloid- $\beta$ oligomer-induced behavioural deterioration in vivo. Behav Brain Res 2010;210(01):32-37

86 Nakagami Y, Nishimura S, Murasugi T, et al. A novel beta-sheet breaker, RS-0406, reverses amyloid beta-induced cytotoxicity and impairment of long-term potentiation in vitro. $\mathrm{Br} \mathrm{J}$ Pharmacol 2002;137(05):676-682

87 Mohamed T, Shakeri A, Rao PP. Amyloid cascade in Alzheimer's disease: recent advances in medicinal chemistry. Eur J Med Chem 2016;113:258-272

88 López LC, Dos-Reis S, Espargaró A, et al. Discovery of novel inhibitors of amyloid $\beta$-peptide 1-42 aggregation. J Med Chem 2012;55(22):9521-9530

89 Luo W, Li YP, He Y, et al. Design, synthesis and evaluation of novel tacrine-multialkoxybenzene hybrids as dual inhibitors for cholinesterases and amyloid beta aggregation. Bioorg Med Chem 2011;19(02):763-770

90 Arai T, Araya T, Sasaki D, et al. Rational design and identification of a non-peptidic aggregation inhibitor of amyloidb based on a pharmacophore motif obtained from cyclo[-Lys-Leu-Val-PhePhe-]. Angew Chem Int Ed Engl 2014;53(31):8236-8239

91 Guzior N, Bajda M, Skrok M, et al. Development of multifunctional, heterodimeric isoindoline-1,3-dione derivatives as cholinesterase and $\beta$-amyloid aggregation inhibitors with neuroprotective properties. Eur J Med Chem 2015;92:738-749

92 Kroth H, Ansaloni A, Varisco Y, et al. Discovery and structure activity relationship of small molecule inhibitors of toxic $\beta$ amyloid-42 fibril formation. J Biol Chem 2012;287(41): 34786-34800

93 Veloso AJ, Dhar D, Chow AM, et al. sym-Triazines for directed multitarget modulation of cholinesterases and amyloid- $\beta$ in Alzheimer's disease. ACS Chem Neurosci 2013;4(02):339-349

94 Cummings J, Lee G, Ritter A, Sabbagh M, Zhong K. Alzheimer's disease drug development pipeline: 2019. Alzheimers Dement (N Y) 2019;5:272-293

95 Cummings J, Lee G, Ritter A, Zhong K. Alzheimer's disease drug development pipeline: 2018. Alzheimers Dement (N Y) 2018; $4: 195-214$ 